

\title{
Implementation of a combo videolaryngoscope for intubation in critically ill patients: a before-after comparative study
}

Audrey de Jong, Noémie Clavieras, Matthieu Conseil, Yannaël Coisel, Pierre-Henri Moury, Yvan Pouzeratte, Moussa Cisse, Fouad Belafia, Boris Jung, Gerald Chanques, et al.

\section{To cite this version:}

Audrey de Jong, Noémie Clavieras, Matthieu Conseil, Yannaël Coisel, Pierre-Henri Moury, et al.. Implementation of a combo videolaryngoscope for intubation in critically ill patients: a before-after comparative study. Intensive Care Medicine, 2013, 10.1007/s00134-013-3099-1 . hal-02549939

\section{HAL Id: hal-02549939 \\ https://hal.umontpellier.fr/hal-02549939}

Submitted on 21 Apr 2020

HAL is a multi-disciplinary open access archive for the deposit and dissemination of scientific research documents, whether they are published or not. The documents may come from teaching and research institutions in France or abroad, or from public or private research centers.
L'archive ouverte pluridisciplinaire HAL, est destinée au dépôt et à la diffusion de documents scientifiques de niveau recherche, publiés ou non, émanant des établissements d'enseignement et de recherche français ou étrangers, des laboratoires publics ou privés. 
Audrey De Jong

Noémie Clavieras

Matthieu Conseil

Yannael Coisel

Pierre-Henri Moury

Yvan Pouzeratte

Moussa Cisse

Fouad Belafia

Boris Jung

Gérald Chanques

Nicolas Molinari

Samir Jaber

\section{Implementation of a combo videolaryngoscope for intubation in critically ill patients: a before-after comparative study}

S. Jaber (

Intensive Care Unit, Anesthesia and Critical Care Department, Saint Eloi Teaching Hospital, University Montpellier 1, 80 avenue Augustin Fliche, 34295 Montpellier CEDEX 5, France

Take-home message: A qualityimprovement process for airway management in ICU implementing systematic use of a mixed

videolaryngoscope decreased the incidence of difficult intubation and/or difficult laryngoscopy.

ClinicalTrials.gov Identifier: NCT01816217.

e-mail: s-jaber@chu-montpellier.fr

Tel.: +33-4-67337271

Abstract Purpose: Airway management in intensive care unit (ICU) patients is challenging. The main objective of this study was to com-
A. De Jong - N. Clavieras - M. Conseil . Y. Coisel · P.-H. Moury - Y. Pouzeratte · M. Cisse - F. Belafia .

B. Jung - G. Chanques - S. Jaber Intensive Care and Anesthesiology Department, Saint Eloi Hospital, University of Montpellier, Montpellier, France

B. Jung - G. Chanques $\cdot$ S. Jaber Unité U1046 de l'Institut National de la Santé et de la Recherche Médicale (INSERM), University of Montpellier, Montpellier, France

\section{N. Molinari}

Department of Statistics, University of Montpellier Lapeyronie Hospital, UMR 729 MISTEA, Montpellier, France
Fax: +33-4-673374 48 pare the incidence of difficult laryngoscopy and/or difficult intubation between a combo videolaryngoscope and the standard Macintosh laryngoscope in critically ill patients. Methods: In the context of the implementation of a qualityimprovement process for airway management, we performed a prospective interventional monocenter before-after study which evaluated a new combo videolaryngoscope. The primary outcome was the incidence of difficult laryngoscopy (defined by Cormack grade 3-4) and/or difficult intubation (more than two attempts). The secondary outcomes were the severe life-threatening complications related to intubation in ICU and the rate of difficult intubation in cases of predicted difficult intubation evaluated by a specific score (MACOCHA score $\geq 3$ ). Results: Two hundred and ten non-selected consecutive intubation procedures were included, 140 in the standard laryngoscope group and 70 in the combo videolaryngoscope group. The incidence of difficult laryngoscopy and/or difficult intubation was $16 \%$ in the laryngoscope group vs. $4 \%$ in the combo videolaryngoscope group $(p=0.01)$. The severe life-threatening complications related to intubation did not differ between groups (16 vs. $14 \%, p=0.79$ ). Among the 32 patients with a MACOCHA score $\geq 3$, there were significantly more patients with difficult intubation in the standard laryngoscope group in comparison to the combo videolaryngoscope group [12/23 (57\%) vs. 0/9 (0 \%), $p<0.01]$. Conclusions: The systematic use of a combo videolaryngoscope in ICU was associated with a decreased incidence of difficult laryngoscopy and/or difficult intubation.

Keywords Intubation - McGrath Mac · Videolaryngoscope · Macintosh - Critical care . Complications 


\section{Introduction}

Airway management in intensive care unit (ICU) patients is challenging [1]. New videolaryngoscope devices are proposed to improve airway management [2]. However, most of the studies comparing videolaryngoscope with a standard laryngoscope have been performed in operating rooms [3, 4]. The role of videolaryngoscopy is still discussed, and particularly in ICU, where there is lack of scientific evidence and worse intubation conditions than in the operating room [5]. The new combo videolaryngoscopes can be used as a direct or indirect view laryngoscope. Literature available comparing videolaryngoscopes with the Macintosh laryngoscope in ICU is poor [6-8]. We aimed to compare difficult laryngoscopy and/or difficult intubation between a new combo videolaryngoscope and the standard Macintosh laryngoscope in critically ill patients in a prospective interventional study.

The present study was conducted to test the hypothesis that the implementation of a quality-improvement process for airway management using a new combo videolaryngoscope would be associated with a decreased incidence of difficult laryngoscopy and/or difficult intubation.

\section{Methods}

Study design and population

We evaluated the implementation of a quality-improvement process for airway management using a new videolaryngoscope in a prospective before-after study performed in a single 16-bed medical-surgical ICU in a teaching hospital. All adult patients consecutively intubated in ICU were included. Exclusion criteria were pregnancy or age under 18 years old. Each intubation procedure was taken into account for analysis when a patient had been intubated twice or more. Two phases were conducted, a non-interventional phase and an interventional phase, separated by a period of training on a manikin. During both phases, the ICU intubation bundle management protocol previously implemented in our unit [9] was applied (see the electronic supplementary material). Note that in this ICU intubation bundle [9] no specific airway management algorithm was used. In the non-interventional phase, all intubations were performed according to the unit standard of care using the standard Macintosh laryngoscope for intubation procedure and were considered as the "standard laryngoscope" group (control group). Part of the data of the non-interventional phase was previously published [1]. Then 6 weeks of interphase training was conducted on two manikins with the new McGrath Mac videolaryngoscope. Finally, the "interventional phase" started, during which all

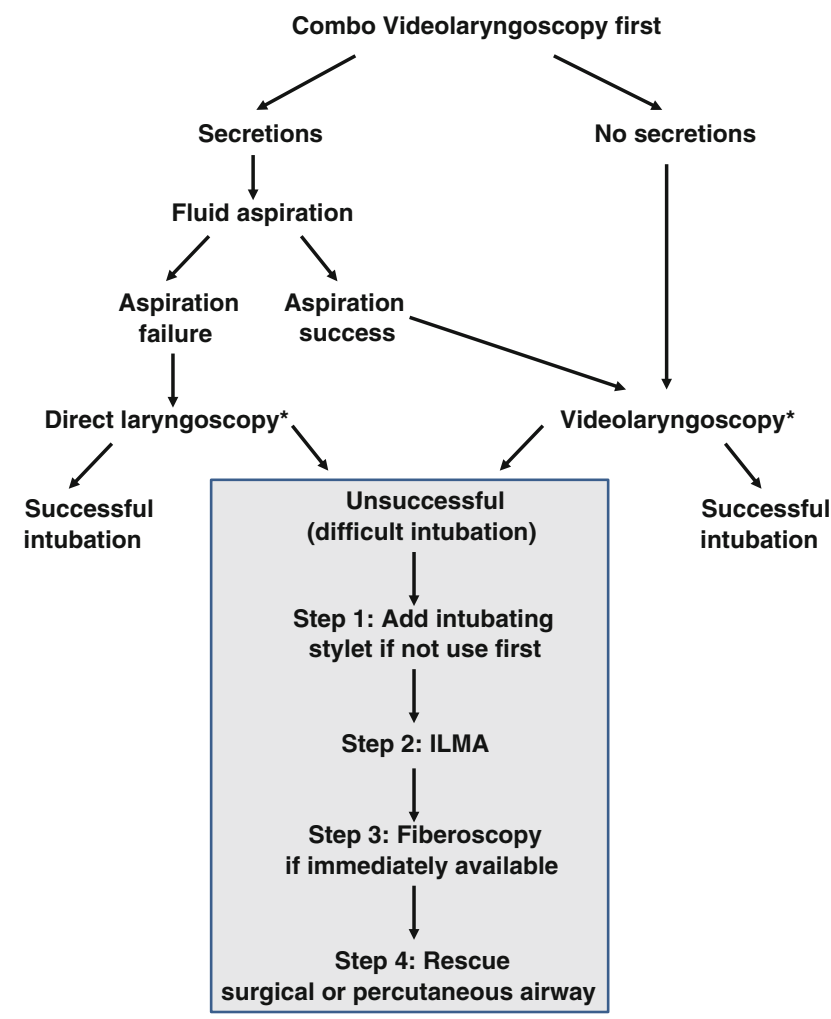

Fig. 1 Airway management algorithm. This airway management algorithm was implemented in the second part of the study, during the interventional phase. ILMA intubation laryngeal mask airway. Asterisk indicates that use of intubating stylets was left to the physician's discretion for the first attempt of intubation

intubations were performed with the McGrath Mac combo videolaryngoscope and constituted the "combo videolaryngoscope" group. An airway management algorithm was implemented (Fig. 1).

\section{Ethics and consent}

Because of the observational, non-invasive design of this study, the need for written consent was waived. The local ethics committee "Comité de Protection des Personnes Sud-Mediterranée III" approved the study design (code UF: 8977, register: 2012-A00651-42). The study was registered on clinicaltrials.gov (identifier no. NCT01816217).

\section{Data collection}

We used the same methodology that we reported in previous studies [1]. Briefly, clinical parameters were prospectively assessed before, during, and after the intubation procedure. 
Before intubation, the following were assessed: demographic data, body mass index, severity scores (Simplified Acute Physiologic Score II [10] at admission, Sequential Organ Failure Assessment [11] score on the day of the procedure), type of admission (medical vs. surgical), cause of admission, cause of intubation (coma was defined as a Glasgow score $<8$ ), date and hour of intubation (daytime procedure was defined as performed from 8 am to $7 \mathrm{pm}$, otherwise it was an on-call procedure), a previous intubation in the last 2 weeks, the nature and number of the operators (expert operators were anesthesiologists and intensivists with experience in intubation procedures $>5$ years and experience in ICU $>1$ year, an operator was defined as an anesthesiologist if he had a formal anesthetic training of more than 24 months) [12], fluid loading, vasopressor use, emergency characteristic of intubation (categorized as follows: real emergency $=$ endotracheal intubation required without any delay, relative emergency $=$ endotracheal intubation required). Before intubation, the following were recorded: preoxygenation, length of preoxygenation $(<3 \mathrm{~min}$, between 3 and $5 \mathrm{~min},>5 \mathrm{~min}$ ), method of preoxygenation [standard vs. non-invasive ventilation (NIV)], difficult mask ventilation (MV) (defined when the physician was not able to provide adequate MV owing to one or more of the following problems: inadequate mask seal, excessive gas leak, or excessive resistance to the ingress or egress of gas) [13], a specific score evaluating the predicted difficulty of intubation in ICU (MACOCHA score) [1], Mallampati score (assessed in a lying position) [14-16], previous documented difficult intubation, thyromental distance (low thyromental distance defined as $<6 \mathrm{~cm}$ ) [15], mouth opening (limited mouth opening defined as $<3.5 \mathrm{~cm}$ ) [16], neck circumference (elevated if more than $40 \mathrm{~cm}$ ) [17], mobility of cervical spine (normal vs. reduced), head and neck pathology, documented obstructive apnea syndrome and Sellick maneuver. Heart rate, arterial pressure and saturation were registered before, during intubation, and in the 30 min after intubation. Drugs and their doses used for intubation and the difficulty of intubation according to the American Society of Anesthesiologists criteria [18] were assessed. Rapid sequence induction and Sellick maneuver were recommended for both non-interventional and interventional phases. The McGrath Mac is a combo videolaryngoscope made from a robust optical polymer and supported by an internal reinforced CameraStick; the combo videolaryngoscope single-use blade delivers a 'steel-like' rigidity. The intubation device was inserted, and the tip of the blade was advanced towards the vallecula. When the combo videolaryngoscope was used as a direct view laryngoscope, the patient was intubated as known from conventional laryngoscopy. When the combo videolaryngoscope was used as an indirect view laryngoscope, the position of the device was adjusted to have the glottis in the center of the screen, and tracheal intubation was performed. The glottis view was assessed (Cormack score) [19]. The Cormack view with the combo videolaryngoscope was defined as was seen on the monitor. Intubation using videolaryngoscope was recommended excepted in cases of persistent secretions after fluid aspiration (Fig. 1). Use of intubating stylets (malleable stylets or long flexible angulated stylets) was left to the physician's discretion for the first attempt of intubation, and recommended in cases of failure of intubation (Fig. 1). A metal blade was used with the direct laryngoscope. An intubation attempt was defined as the introduction of the endotracheal tube past the patient's teeth or as a laryngoscopy failure without the introduction of the endotracheal tube. Finally, the mortality at day 28 after admission was evaluated.

Definition of difficult intubation, difficult

laryngoscopy, and complications

Difficult intubation was defined as three or more laryngoscopic attempts [18] to place the endotracheal tube into the trachea. Difficult laryngoscopy $[18,20]$ was defined as Cormack grade 3 or 4 . Severe life-threatening complications $[9,21]$ were defined as death, cardiac arrest, severe cardiovascular collapse, defined as systolic blood pressure $<65 \mathrm{mmHg}$ recorded at least one time and/or $<90 \mathrm{mmHg}$ that lasted $30 \mathrm{~min}$ despite $500-1,000 \mathrm{ml}$ of fluid loading (crystalloids/or colloids solutions) and/or requiring introduction of vasoactive support, or severe hypoxemia (decrease in $\mathrm{SpO}_{2}$ below $80 \%$ during attempts), occurring during the first hour following intubation.

Mild to moderate complications $[9,21]$ were defined as esophageal intubation, aspiration of gastric contents (migration of stomach contents into the lung), supraventricular and/or ventricular arrhythmia (without pulseless rhythm) that required therapy, dangerous agitation (Richmond Agitation-Sedation Scale score above 3) or dental injury, occurring during the first hour following intubation.

\section{Outcomes}

The primary outcome was the incidence of difficult laryngoscopy and/or difficult intubation. The secondary outcomes were the severe life-threatening complications related to intubation in ICU, the moderate complications related to intubation in ICU, the rate of difficult intubation in cases of predicted difficult intubation (MACOCHA score $\geq 3$ ), the success rate of intubation on the first attempt, the number of intubation attempts, the glottis view (Cormack grade), the difficult intubation, and the difficult laryngoscopy. 


\section{Statistical analysis}

The number of subjects needed was calculated to detect at least a difference of $11 \%$ in the primary endpoint (incidence of difficult laryngoscopy and/or difficult intubation) between combo videolaryngoscope (4\%) and standard Macintosh laryngoscope (15\%), [1] with a power of 0.8 . An intermediate analysis was planned after 70 intubations with the combo videolaryngoscope to assess safety (severe life-threatening complications) and difficult intubation rate and/or difficult laryngoscopy. Taking into account this intermediate analysis, with a corrected risk $\alpha$ at 0.025 after Bonferroni correction, the required sample size was 140 patients in each group. Quantitative variables were expressed as means (standard deviation) or medians (interquartiles 25-75\%) and compared using the Student $t$ test or the Wilcoxon test as appropriate (Gaussian or non-Gaussian variables). Qualitative variables were expressed as numbers (\%) and compared using the $\chi^{2}$ test or the Fisher test as appropriate. A multivariate logistic regression was performed to assess risk factors of difficult laryngoscopy and/or difficult intubation. Statistical significance was considered at $p<0.025$ for intermediate and final analysis.

\section{Results}

We stopped the trial after the planned intermediate analysis because the difficult laryngoscopy and/or difficult intubation rate in the combo videolaryngoscope group was lower than in the standard laryngoscope group $(p<0.01)$. From 1 September 2011 to 31 March 2013, 210 intubation procedures were studied in 206 patients. All the intubation procedures were included. Four patients ( $2 \%$, three in the standard laryngoscope group and one in the combo videolaryngoscope group) were intubated twice. The flow chart of the study is shown in Fig. 2. Two patients were intubated with the standard laryngoscope because the combo videolaryngoscope was not available.

One hundred and forty intubations were performed in the non-interventional phase from 1 September 2011 to 1 September 2012 constituting the standard laryngoscope group and 70 intubations were performed in the interventional phase from 15 October 2012 to 30 March 2013 constituting the combo videolaryngoscope group.

Incidence of difficult laryngoscopy and/or difficult intubation was $16 \%$ (23 of 140 intubation procedures) in the standard laryngoscope group and $4 \%$ (3 of 70 intubation procedures) in the combo videolaryngoscope group $(p=0.01)$.

Both groups were comparable (Tables 1 and E1 in the electronic supplementary material). Operator status and main variables obtained before intubation, the predictive factors of difficult intubation, and the main parameters in

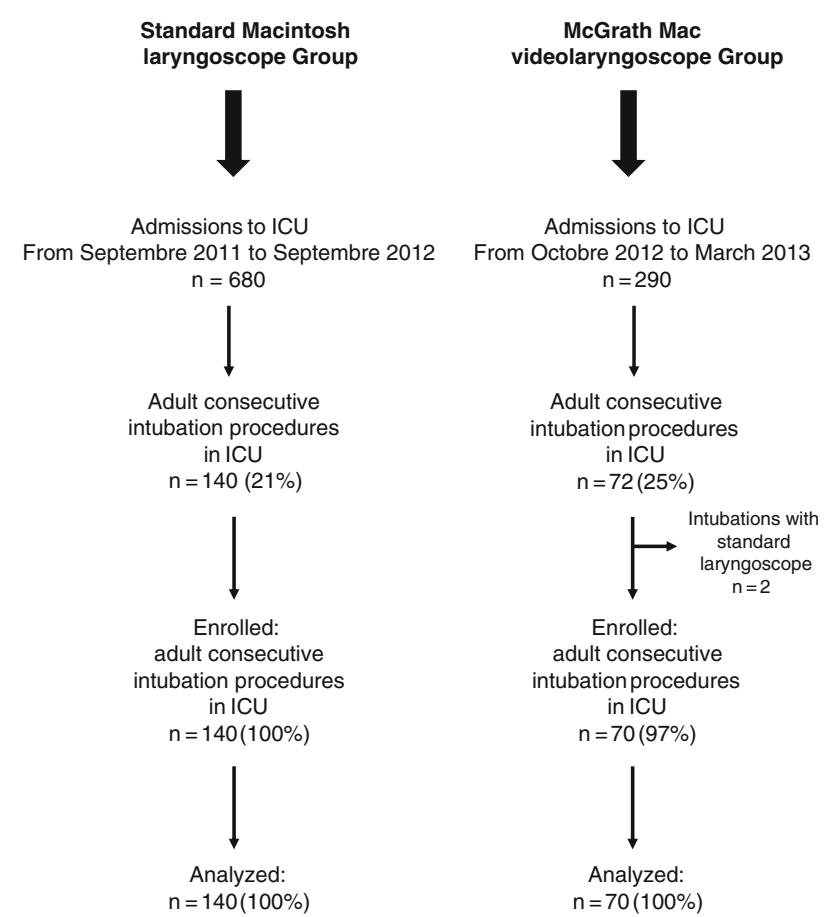

Fig. 2 Patient flow diagram

both groups did not differ, apart from a decreased rate of expert operators in the combo videolaryngoscope group (Table 1). The drugs used for intubation did not differ between groups, except for ketamine and suxamethonium which were used more in the combo videolaryngoscope group (Table E2 in the electronic supplementary material).

The severe life-threatening and moderate complications related to intubation did not differ between groups (Table 2). Mortality at day 28 was of 54/140 (39\%) in the standard laryngoscope group and 29/70 (41\%) in the combo videolaryngoscope group $(p=0.69)$. Mortality at day 2 was of $38 / 140(27 \%)$ in the standard laryngoscope group and was $10 / 70(14 \%)$ in the combo videolaryngoscope group $(p=0.03)$.

The median number of intubation attempts was 1 (1-2) in the standard laryngoscope group vs. 1 (1-1) in the combo videolaryngoscope group $(p=0.09)$. The number of successful intubations on the first attempt was $96(69 \%)$ in the standard laryngoscope group vs. 55 $(79 \%)$ in the combo videolaryngoscope group $(p=0.13)$. The median Cormack rate was $1(1-2)$ in the standard laryngoscope group vs. 1 (1-1) in the combo videolaryngoscope group $(p=0.03)$. The number of difficult intubations and difficult laryngoscopies 19 $(14 \%)$ and $7(5 \%)$ in the standard laryngoscope group vs. $3(4 \%)$ and $2(3 \%)$ in the combo videolaryngoscope group $(p=0.05, p=0.72)$. Figure 3 depicts the frequency of difficult laryngoscopy and/or difficult intubation, difficult intubation, and difficult laryngoscopy according to group. 
Table 1 Characteristics of patients and operators in standard laryngoscope and combo videolaryngoscope groups

\begin{tabular}{|c|c|c|c|c|}
\hline & Total $(n=210)$ & $\begin{array}{l}\text { Standard } \\
\text { laryngoscope group } \\
(n=140)\end{array}$ & $\begin{array}{l}\text { Combo } \\
\text { videolaryngoscope } \\
\text { group }(n=70)\end{array}$ & $p$ value \\
\hline Age, years & $60(50-69)$ & $59(49-69)$ & $63(55-70)$ & 0.15 \\
\hline Male, gender & $133 / 208(64)$ & $87(63)$ & $46(67)$ & 0.56 \\
\hline SAPS2 & $44(35-58)$ & $43(34-60)$ & $44(38-49)$ & 0.90 \\
\hline SOFA & $7(5-10)$ & $7(4-9)$ & $7(5-10)$ & 0.36 \\
\hline Weight, kg & $70(61-85)$ & $70(61-84)$ & $75(62-89)$ & 0.14 \\
\hline Height, $\mathrm{cm}$ & $170(164-175)$ & $170(160-175)$ & $170(165-175)$ & 0.18 \\
\hline BMI, $\mathrm{kg} / \mathrm{m}^{2}$ & $25(22-29)$ & $25(22-29)$ & $25(22-30)$ & 0.57 \\
\hline Medical type of admission & $137(65)$ & $88(63)$ & $49(70)$ & 0.31 \\
\hline \multicolumn{5}{|l|}{ Reason for ICU admission } \\
\hline Acute respiratory failure & $74(35)$ & $50(36)$ & $31(44)$ & 0.23 \\
\hline Trauma & $0(0)$ & $0(0)$ & $0(0)$ & 1.00 \\
\hline Postoperative & $25(12)$ & $14(10)$ & $11(16)$ & 0.23 \\
\hline Cardiac arrest & $3(1)$ & $1(1))$ & $2(3)$ & 0.26 \\
\hline Neurologic & $39(19)$ & $29(21)$ & $10(14)$ & 0.26 \\
\hline Shock & $58(28)$ & $35(25)$ & $16(23)$ & 0.73 \\
\hline Ascitic decompensation & $22(11)$ & $12(9)$ & $10(14)$ & 0.20 \\
\hline Others & 34 (17) & $25(18)$ & $9(13)$ & 0.35 \\
\hline \multicolumn{5}{|l|}{ Reason for intubation } \\
\hline Acute respiratory failure & $121(58)$ & $75(54)$ & $46(66)$ & 0.09 \\
\hline Shock & $20(10)$ & $13(9)$ & $7(10)$ & 0.87 \\
\hline Coma & $46(22)$ & $31(22)$ & $15(21)$ & 0.91 \\
\hline Cardiac arrest & $4(2)$ & $4(3)$ & $0(0)$ & 0.30 \\
\hline Replace the endotracheal tube & $17(8)$ & $10(7)$ & $7(10)$ & 0.47 \\
\hline Others & $40(19)$ & $29(21)$ & $11(16)$ & 0.38 \\
\hline First intubation & $121(58)$ & $80(57)$ & $41(59)$ & 0.84 \\
\hline Expert operator & $51 / 202(25)$ & $41(30)$ & $10(15)$ & 0.02 \\
\hline Anesthesiologist & $171(81)$ & $113(81)$ & $58(83)$ & 0.71 \\
\hline \multicolumn{4}{|l|}{ Number of operators } & 0.58 \\
\hline 1 & $8 / 207$ & $5(4)$ & $3(4)$ & \\
\hline 2 & $153 / 207$ & $104(74)$ & $49(73)$ & \\
\hline 3 & $46 / 207$ & $31(22)$ & $15(21)$ & \\
\hline \multicolumn{4}{|l|}{ Emergency characteristic of intubation } & 0.19 \\
\hline Real emergency & $27(31)$ & $21(15)$ & $6(9)$ & \\
\hline Relative emergency & $183(55)$ & $119(85)$ & $64(91)$ & \\
\hline Vasopressor use & $45(22)$ & $29(21)$ & $16(23)$ & 0.72 \\
\hline MACOCHA score & & & & 0.91 \\
\hline From 0 to 2 & $178(85)$ & $117(84)$ & $61(87)$ & \\
\hline From 3 to 5 & $13(6)$ & $9(6)$ & $4(6)$ & \\
\hline From 6 to 8 & $15(7)$ & $11(8)$ & $4(6)$ & \\
\hline From 9 to 12 & $4(2)$ & $3(2)$ & $1(1)$ & \\
\hline
\end{tabular}

Data are summarized as $n(\%)$ or median (interquartile range). One SAPS2 Simplified Acute Physiologic Score, SOFA Sequential patient can have more than one reason for ICU admission or for Organ Failure Assessment, ICU intensive care unit intubation

Among the 32 patients with a MACOCHA score $\geq 3$ [1], there were significantly more patients with difficult intubation in the standard laryngoscope group in comparison to the combo videolaryngoscope group $[12 / 23$ $(57 \%)$ vs. $0 / 9(0 \%), p<0.01]$.

In the final multivariate model constructed with the 167 intubation procedures and all available data, adjusted for ketamine and suxamethonium use, the main predictors of difficult intubation, reported as odds ratio (OR) with confidence interval (CI) in parentheses, were the standard laryngoscope group [6.7 (1.25-35.7), $p=0.03$ ], the Mallampati score III or IV [14.4 (4.2-49.1), $p<0.01]$, and the non-expert operator status [6.1 (1.1-33.3), $p=0.04]$.
Airway injuries were observed in none of the groups. The combo videolaryngoscope was used as a direct laryngoscope in 17 patients $(24 \%)$ and as a videolaryngoscope in 53 patients (76\%). In expert operators, the combo videolaryngoscope was used as a direct laryngoscope in $2 / 10$ patients $(20 \%)$ vs. $15 / 60(25 \%)$ in the non experts $(p=0.75)$.

In the combo videolaryngoscope group, no other intubation device was necessary. Intubating stylets were used at first in $17 / 53$ patients (32\%) intubated with an indirect view. In the standard laryngoscope group, intubating stylets were used at first in 15/140 (11\%) patients and added after failure of initial attempt in 7/140 patients 
Table 2 Complications of intubation in standard laryngoscope and combo videolaryngoscope groups

\begin{tabular}{lclll}
\hline & $\begin{array}{l}\text { Total } \\
(n=210)\end{array}$ & $\begin{array}{l}\text { Standard } \\
\text { laryngoscope } \\
\text { group }(n=140)\end{array}$ & $\begin{array}{l}\text { Combo } \\
\text { videolaryngoscope } \\
\text { group }(n=70)\end{array}$ & $p$ value \\
\hline Severe life-threatening complications & $32(14)$ & $22(16)$ & $10(14)$ & 0.79 \\
Death & $0(0)$ & $0(0)$ & $0(0)$ & 1.00 \\
Cardiac arrest & $3(1)$ & $3(2)$ & $0(0)$ & 0.55 \\
Severe cardiovascular collapse & $15(7)$ & $11(8)$ & $4(6)$ & 0.86 \\
Severe hypoxemia & $17(7)$ & $11(8)$ & $6(9)$ & 0.70 \\
Mild to moderate complications & $21(10)$ & $16(11)$ & $5(7)$ & 0.33 \\
Esophageal intubation & $12(6)$ & $8(6)$ & $4(6)$ & 0.00 \\
Aspiration of gastric contents & $2(1)$ & $2(1)$ & $0(0)$ & 1.00 \\
Arrhythmia & $4(2)$ & $3(2)$ & $1(1)$ & 1.00 \\
Dental injury & $0(0)$ & $0(0)$ & $0(0)$ & 0.55 \\
Agitation & $3(1)$ & $3(2)$ & $0(0)$ & \\
\hline
\end{tabular}

Data are summarized as $n(\%)$

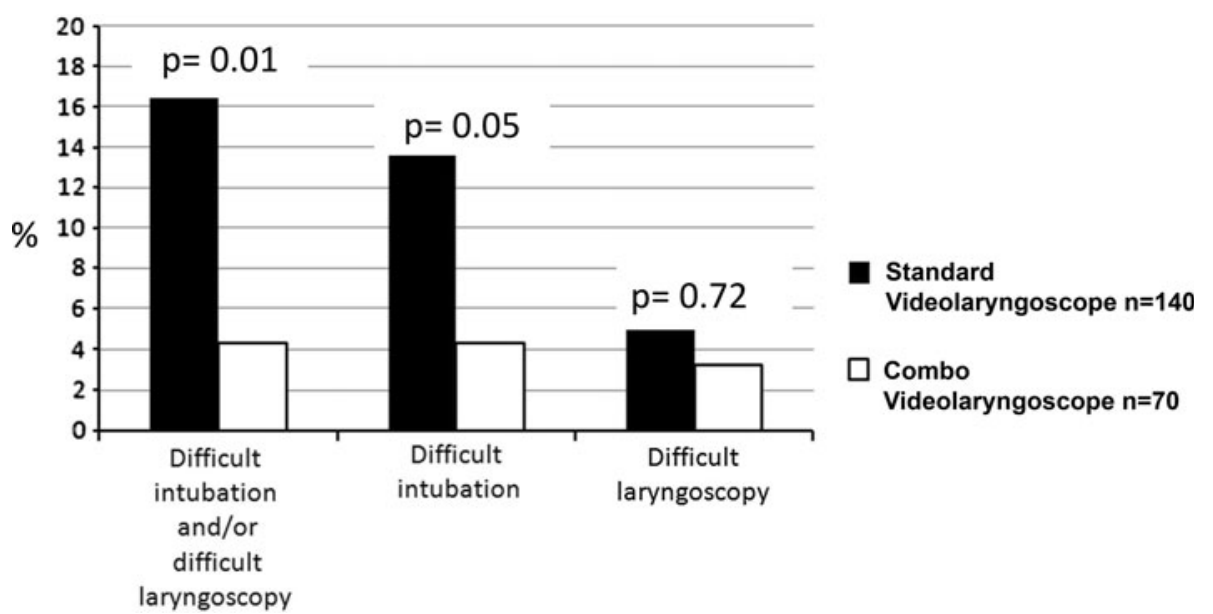

Fig. 3 Frequency of difficult laryngoscopy and/or difficult intubation, difficult intubation and difficult laryngoscopy according to group. Incidence of difficult laryngoscopy and/or difficult intubation was $16 \%$ (23 of 140 intubation procedures) in the standard laryngoscope group and $4 \%$ (3 of 70 intubation procedures) in the

(5\%). Two fiberoscopies and two rescue emergency tracheotomies were used.

\section{Discussion}

This is the first study in critically ill patients to assess the implementation of a quality-improvement process for airway management using a new combo videolaryngoscope, which can be used as a direct or indirect view laryngoscope. Anticipating difficult intubation is a challenging issue in ICU; difficult intubation is very frequent (up to $23 \%$ [22]) and associated with severe life-threatening complications [1, 9, 21, 23].

This study shows that the systematic use of a combo videolaryngoscope for intubation significantly reduces the combo videolaryngoscope group $(p=0.01)$. The number of difficult intubations and difficult laryngoscopies was respectively $19(14 \%)$ and $7(5 \%)$ in the standard laryngoscope group vs. 3 $(4 \%)$ and $2(3 \%)$ in the combo videolaryngoscope group $(p=0.05, p=0.72)$

incidence of difficult laryngoscopy and/or difficult intubation (Fig. 3). In multivariate analysis, being in the standard laryngoscope group was an independent risk factor of difficult laryngoscopy and/or difficult intubation, as were Mallampati score III or IV and non-expert operator status. Those results are concordant with previous studies [1, 12].

Moreover, in the subgroup of patients with difficult intubation predicted by the MACOCHA score [1], incidence of difficult intubation was much higher in the standard laryngoscope group $(47 \%)$ than in the combo videolaryngoscope group $(0 \%)$. The use of the combo videolaryngoscope could be of even more interest in this subgroup of patients with predictive criteria of difficult intubation. Indeed, the criteria predicting difficult intubation in ICU with standard laryngoscope seem poorly adapted to the videolaryngoscope. The main challenge 
with the videolaryngoscope is more to enter the tube into the trachea than visualizing the glottis. It is sometimes hard to advance the tube into the trachea because the tube has to pass a sharp angle to enter the larynx. An intubating stylet could help in this case and was used in $32 \%$ of patients intubated in the indirect view. The decreased incidence of difficult laryngoscopy in the combo videolaryngoscope group was not significant possibly because of a lack of power given the low incidence of difficult laryngoscopy in the standard laryngoscope group (4\%).

The rates of severe life-threatening and moderate complications were comparable to those in our previous study [9], after implementation of a bundle with the aim to reduce these complications. This study of two other series of patients confirms that the bundle works and that it is difficult to further reduce complications of intubation, even with a new intubation device, as also noticed in a study by Lakticova et al. [8]. The low rate of complications compared to other studies $[1,23]$ could be explained by the strong experience of our center. Indeed, we have worked on this topic for more than 10 years [1, 9, 21, 24].

Systematic use of combo videolaryngoscope in ICU could be discussed given the lower rate of difficult laryngoscopy and/or difficult intubation (Fig. 2), without airway injury in any of the groups. These airway injuries are dreaded with devices that provide only an indirect laryngoscopic view $[25,26]$. The combo videolaryngoscope offers the advantage of possibly being used as a direct laryngoscope and to be used without any rigidifying tool responsible for the airway trauma. The airway management algorithm (Fig. 1) recommends using the combo videolaryngoscope as an indirect laryngoscope, except in case of abundant secretions. This explains why it could be useful to have such a polyvalent device in the ICU setting. In the present study, the operators chose most of the time to use it as an indirect laryngoscope, as advised by the airway management algorithm. The main explanation is that especially in ICU, the physicians feel safer further away from the mouth of the patient and their secretions. Other videolaryngoscopes [6, 7, 27] could be at least as efficient as the McGrath Mac in the difficult airway setting in ICU.

Several limitations should be underlined before applying our results to clinical practice. First, this is a quality-improvement process with a before-after design, monocenter, observational, and unblinded study. We did not randomize the patients which weakens the conclusions that we can draw. However, there was a control group, the data were prospectively recorded, and both groups were comparable (Table 1). Nevertheless, qualityimprovement studies are susceptible to changes in rates of endpoints over time, independent of the measures taken [28]: the combo videolaryngoscope is probably not the only explanation for the good results of the study, because quality-improvement studies induce general trends toward improved patient management [29, 30]. Moreover, airway management algorithms also demonstrated their efficiency in previous studies [31]. The intubation bundle could explain the good results of the study. However, the intubation bundle was already implemented in the first part of the study [9]. Second, the team was trained during 6 weeks before starting the second part of the study, and these results were obtained in a single ICU highly experienced in intubation $[1,9,21,24]$. The results may not be so favorable if the combo videolaryngoscope was used for the first time in an inexperienced center. However, the operators were less expert in the videolaryngoscope part of the study (15\% of expert operators) in comparison with the standard laryngoscope part of the study (30\% of expert operators). In spite of the decreased percentage of expert operators, the airway management was improved with the combo videolaryngoscope. It should be pointed out that every intubation procedure was supervised by a senior physician. Thus, an increased proportion of laryngoscopies by junior operators in the intervention group might be due to an increase in team confidence in laryngoscopy with the combo videolaryngoscope. This is consistent with the primary endpoint. Fourth, the use of ketamine and suxamethonium was higher in the combo videolaryngoscope group. However, when adjusted for ketamine and suxamethonium use, the combo videolaryngoscope remained a protective factor of difficult laryngoscopy and/or difficult intubation. Finally, after the primary endpoint was reached, we stopped the study prematurely. Indeed, this intermediate analysis was planned in the protocol and we thought the combo videolaryngoscope use in ICU should be generalized in our hospital because of the positive results. The decrease of complications was not significant at this intermediate analysis; however, complications related to intubation were secondary endpoints and the study was not powered to highlight a difference in complication rates between standard laryngoscope and combo videolaryngoscope groups.

In conclusion, a quality-improvement process with systematic use of a combo videolaryngoscope in ICU was associated with a decrease in the incidence of difficult intubation or/and difficult laryngoscopy. In addition, predicted difficult intubations were dramatically decreased by using the combo videolaryngoscope. Further randomized controlled studies are required to confirm these results, assess if reducing the incidence of difficult laryngoscopy and/or difficult intubation could reduce the complications related to intubation, and to determine the role of videolaryngoscopes in ICU.

Acknowledgments The authors are grateful to Valérie Macioce, Statistic Department, La Colombière University Hospital, Centre Hospitalier Universitaire Montpellier, Montpellier, 34295, France for her English editing.

Conflicts of interest The authors declare that they have no conflict of interest related to the subject of the study. 


\section{References}

1. De Jong A, Molinari N, Terzi N, Mongardon N, Arnal J-M, Guitton C, Allaouchiche B, Paugam-Burtz C, Constantin J-M, Lefrant J-Y, Leone M, Papazian L, Asehnoune K, Maziers N, Azoulay E, Pradel G, Jung B, Jaber S (2013) Early identification of patients at risk for difficult intubation in ICU: development and validation of the MACOCHA score in a multicenter cohort study. Am J Respir Crit Care Med 187:832-839. doi: 10.1164/rccm.201210-1851OC

2. Asai T (2012) Videolaryngoscopes: do they truly have roles in difficult airways? Anesthesiology 116:515-517. doi:10.1097/ALN.0b013e318246e866

3. Aziz MF, Healy D, Kheterpal S et al (2011) Routine clinical practice effectiveness of the Glidescope in difficult airway management: an analysis of 2,004 Glidescope intubations, complications, and failures from two institutions. Anesthesiology 114:34-41. doi: 10.1097/ALN.0b013e3182023eb7

4. Aziz MF, Dillman D, Fu R, Brambrink AM (2012) Comparative effectiveness of the C-MAC video laryngoscope versus direct laryngoscopy in the setting of the predicted difficult airway. Anesthesiology 116:629-636. doi: 10.1097/ALN.0b013e318246ea34

5. Cook T, Behringer EC, Benger J (2012) Airway management outside the operating room: hazardous and incompletely studied. Curr Opin Anaesthesiol 25:461-469. doi: 10.1097/ACO.0b013e32835528b1

6. Noppens RR, Geimer S, Eisel N et al (2012) Endotracheal intubation using the C-MAC ${ }^{\circledR}$ video laryngoscope or the Macintosh laryngoscope: a prospective, comparative study in the ICU. Crit Care 16:R103. doi:10.1186/cc11384

7. Kory P, Guevarra K, Mathew JP et al (2013) The impact of video laryngoscopy use during urgent endotracheal intubation in the critically ill. Anesth Analg. doi: 10.1213/ANE.0b013e3182917f2a

8. Lakticova V, Koenig SJ, Narasimhan M, Mayo PH (2013) Video laryngoscopy is associated with increased first pass success and decreased rate of esophageal intubations during urgent endotracheal intubation in a medical intensive care unit when compared to direct laryngoscopy. J Intensive Care Med. doi:10.1177/0885066613492641
9. Jaber S, Jung B, Corne P et al (2010) An intervention to decrease complications related to endotracheal intubation in the intensive care unit: a prospective, multiple-center study. Intensive Care Med 36:248-255. doi: 10.1007/s00134-009-1717-8

10. Le Gall JR, Lemeshow S, Saulnier F (1993) A new simplified acute physiology score (SAPS II) based on a European/North American multicenter study. JAMA 270:2957-2963

11. Vincent JL, Moreno R, Takala J et al (1996) The SOFA (Sepsis-Related Organ Failure Assessment) score to describe organ dysfunction/failure. On behalf of the Working Group on SepsisRelated Problems of the European Society of Intensive Care Medicine. Intensive Care Med 22:707-710

12. Simpson GD, Ross MJ, McKeown DW, Ray DC (2012) Tracheal intubation in the critically ill: a multi-centre national study of practice and complications. $\mathrm{Br}$ J Anaesth 108:792-799. doi: 10.1093/bja/aer504

13. Singhal V, Sharma M, Prabhakar $\mathrm{H}$ et al (2009) Effect of posture on mouth opening and modified Mallampati classification for airway assessment. J Anesth 23:463-465. doi: 10.1007/s00540-009-0761-4

14. Tham EJ, Gildersleve CD, Sanders LD et al (1992) Effects of posture, phonation and observer on Mallampati classification. Br J Anaesth 68:32-38

15. Lewis M, Keramati S, Benumof JL, Berry CC (1994) What is the best way to determine oropharyngeal classification and mandibular space length to predict difficult laryngoscopy? Anesthesiology 81:69-75

16. Calder I, Picard J, Chapman $\mathrm{M}$ et al (2003) Mouth opening: a new angle. Anesthesiology 99:799-801

17. Gonzalez H, Minville V, Delanoue K, Mazerolles M, Concina D, Fourcade O (2008) The importance of increased neck circumference to intubation difficulties in obese patients. Anesth Analg 106:1132-1136

18. Apfelbaum JL, Hagberg CA, Caplan RA et al (2013) Practice guidelines for management of the difficult airway: An updated report by the American Society of Anesthesiologists Task Force on Management of the Difficult Airway. Anesthesiology 118:251-270. doi: 10.1097/ALN.0b013e31827773b2

19. Cormack RS, Lehane J (1984) Difficult tracheal intubation in obstetrics. Anaesthesia 39:1105-1111
20. Ayoub C, Baraka A, el-Khatib M et al (2000) A new cut-off point of thyromental distance for prediction of difficult airway. Middle East J Anesthesiol 15:619-633

21. Jaber S, Amraoui J, Lefrant J-Y et al (2006) Clinical practice and risk factors for immediate complications of endotracheal intubation in the intensive care unit: a prospective, multiple-center study. Crit Care Med 34:2355-2361. doi:10.1097/01.CCM.0000233879. 58720.87

22. Heuer JF, Barwing TA, Barwing $\mathrm{J}$ et al (2012) Incidence of difficult intubation in intensive care patients: analysis of contributing factors. Anaesth Intensive Care 40:120-127

23. Griesdale DEG, Bosma TL, Kurth T et al (2008) Complications of endotracheal intubation in the critically ill. Intensive Care Med 34:1835-1842. doi:10.1007/s00134-008-1205-6

24. Baillard C, Fosse J-P, Sebbane M et al (2006) Noninvasive ventilation improves preoxygenation before intubation of hypoxic patients. Am J Respir Crit Care Med 174:171-177. doi:10.1164/rccm.200509-1507OC

25. Cooper RM (2010) Reducing the risks associated with videolaryngoscopy. Anesth Analg 111:244; author reply 244. doi:10.1213/ANE.0b013e3181d $\mathrm{d} 8 \mathrm{~b} 4 \mathrm{f}$

26. Cavus E, Kieckhaefer J, Doerges V et al (2010) The C-MAC videolaryngoscope: first experiences with a new device for videolaryngoscopy-guided intubation. Anesth Analg 110:473-477. doi: 10.1213/ANE.0b013e3181c5bce5

27. Ng I, Hill AL, Williams DL et al (2012) Randomized controlled trial comparing the McGrath videolaryngoscope with the C-MAC videolaryngoscope in intubating adult patients with potential difficult airways. Br J Anaesth 109:439-443. doi:10.1093/bja/aes 145

28. Levy MM, Dellinger RP, Townsend SR et al (2010) The Surviving Sepsis Campaign: results of an international guideline-based performance improvement program targeting severe sepsis. Intensive Care Med 36:222-231. doi:10.1007/s00134-009-1738-3 
29. Ananda-Rajah MR, McBryde ES, Buising KL et al (2010) The role of general quality improvement measures in decreasing the burden of endemic MRSA in a medical-surgical intensive care unit. Intensive Care Med 36:1890-1898. doi:10.1007/s00134$010-2019-x$
30. Misset B, Timsit J-F, Dumay M-F et al 31. Amathieu R, Combes X, Abdi W et al (2004) A continuous qualityimprovement program reduces nosocomial infection rates in the ICU. Intensive Care Med 30:395-400. doi: 10.1007/s00134-003-2096-1 (2011) An algorithm for difficult airway management, modified for modern optical devices (Airtraq laryngoscope; LMA CTrach $^{\mathrm{TM}}$ ): a 2-year prospective validation in patients for elective abdominal, gynecologic, and thyroid surgery. Anesthesiology 114:25-33. doi:10.1097/ALN.0b013e318201c44f 